\title{
Sistem Informasi Lowongan Kerja di Kota Sampit Berbasis Web
}

\author{
Puput Nada Musfika*, Depi Rusda \\ Fakultas Ilmu Komputer, Jurusan Sistem Informasi, Universitas Darwan Ali, Sampit, Indonesia \\ Email: 1," puputnada4@gmail.com, ${ }^{2}$ dprusda_wk@yahoo.com
}

\begin{abstract}
Abstrak
Kebutuhan informasi sangatlah diperlukan seiring dengan kemajuan teknologi yang begitu pesat di zaman modern seperti pada saat ini, terutama penggunaan sistem komputerisasi yang merambat di segala bidang. Sehingga, setiap Sumber Daya Manusia (SDM) harus senantiasa dituntut untuk memenuhi keahlian, keterampilan maupun kemampuan dalam menjalankan suatu perangkat keras maupun perangkat lunak komputer. Dalam bidang jasa penyampaian informasi pada sebuah perusahaan ataupun instansi-instansi yang memerlukan tenaga kerja seperti yang ada di Kota Sampit Kalimantan Tengah, saat ini informasi yang disampaikan hanya melalui beberapa media seperti koran, majalah, dan informasi yang didapatkan dari mulut ke mulut. Hal ini menyebabkan sulitnya menemukan informasi yang akurat bagi para pelamar kerja, dan bagi pihak perusahaan juga sulit menemukan calon karyawan dengan waktu yang efisien karena masih dilakukan tanpa adanya sebuah sistem informasi. Dengan berkembangnya teknologi informasi, maka perlu disediakan sebuah Sistem Informasi untuk mengatasi permasalahan dalam penyampaian sebuah informasi lowongan pekerjaan dari perusahaan-perusahaan secara langsung. Dengan adanya Sistem Informasi tersebut para pelamar juga akan mendapatkan kemudahan untuk menerima informasi, menyerahkan berkas lamaran kerja, dan mengerjakan tes tertulis secara online. Serta pihak perusahaan akan mendapatkan karyawan melalui cara yang efektif dengan waktu yang efisien, dimulai dari penyampaian informasi, penyeleksian berkas, tes tertulis dan hasil kelulusan dari tes tertulis yang bisa langsung di proses melalui sistem informasi ini.
\end{abstract}

Kata Kunci: Teknologi; Sistem; Informasi; Lowongan; Online.

\begin{abstract}
The need for information is very much needed in line with the rapid technological advances in modern times such as today, especially the use of computerized systems that propagate in all fields. So, every Human Resource (HR) must always be required to fulfill the expertise, skills and abilities in running a computer hardware or software. In the field of information delivery services to companies or agencies that require labor, such as those in Sampit City, Central Borneo, currently information is conveyed only through several media such as newspapers, magazines, and information obtained by word of mouth. This makes it difficult to find accurate information for job applicants, and for companies it is also difficult to find prospective employees in a time efficient manner because it is still done without an information system. With the development of information technology, it is necessary to provide an Information System to solve problems in delivering job information directly from companies. With this Information System, applicants will also find it easy to receive information, submit job application files, and take written tests online. And the company will get employees in an effective and time-efficient way, starting from the delivery of information, file selection, written tests and passing results from written tests that can be processed directly through this information system.
\end{abstract}

Keywords: Technology; System; Information; Vacancies; Online

\section{PENDAHULUAN}

Kebutuhan informasi sangatlah diperlukan seiring dengan kemajuan teknologi yang begitu pesat di zaman modern seperti pada saat ini, terutama penggunaan sistem komputerisasi yang merambat di segala bidang. Sehingga, setiap Sumber Daya Manusia (SDM) harus senantiasa dituntut untuk memenuhi keahlian, keterampilan maupun kemampuan dalam menjalankan suatu perangkat keras maupun perangkat lunak komputer[1].

Dengan adanya hal tersebut telah membawa masyarakat kepada perkembangan yang baik. Banyak sekali manfaat serta kemudahan yang telah dihasilkan dengan perkembangan teknologi. Penerapan teknologi informasi dapat dilihat diberbagai macam bidang seperti pendidikan, pekerjaan, dan aktivitas-aktivitas lain yang ada dalam keseharian manusia. Selain itu manusia juga membutuhkan sebuah informasi yang disajikan secara tepat,banyak cara yang dilakukan untuk memperoleh informasi salah satunya melalui internet.dan untuk penyampaian informasi serta tempat untuk meletakkan informasi secara online didunia internet dikenal dengan sebutan web. Selain sebagai sarana penyaji informasi, web juga biasanya digunakan oleh masyarakat sebagai media untuk melakukan berbagai aktifitas[2].

Pelayanan penyampaian informasi merupakan upaya pemenuhan kebutuhan dan keinginan masyarakat yang ingin mencari pekerjaan serta ketepatan penyampaian informasi untuk mengimbangi harapan para pencari kerja. Sebagai segala bentuk aktivitas yang diberikan oleh suatu pihak yang lain atau masyarakat dengan tujuan dapat memberikan kepuasan kepada masyarakat untuk memenuhi kebutuhan informasi.

Dalam bidang jasa penyampaian informasi pada sebuah perusahaan ataupun instansi-instansi yang memerlukan tenaga kerja seperti yang ada di Kota Sampit Kalimantan Tengah, saat ini informasi yang disampaikan hanya melalui beberapa media seperti koran, majalah, dan informasi yang didapatkan dari mulut ke mulut. Hal ini menyebabkan sulitnya menemukan informasi yang akurat bagi para pelamar kerja, dan bagi pihak perusahaan juga sulit menemukan calon karyawan dengan waktu yang efisien karena saat ini proses yang berjalan terlalu memakan waktu yang banyak, dari penyampaian informasi, penyeleksian berkas, pelaksanaan tes tertulis dan yang terakhir penyampaian kelulusan berkas dan tes karyawan yang semuanya masih dilakukan tanpa sebuah sistem informasi. 
Oleh karena itu, dengan berkembangnya teknologi informasi, maka perlu disediakan sebuah Sistem Informasi untuk mengatasi permasalahan dalam penyampaian sebuah informasi lowongan pekerjaan dari perusahaan-perusahaan secara langsung[1]. Dengan adanya Sistem Informasi tersebut para pelamar juga akan mendapatkan kemudahan untuk menerima informasi, menyerahkan berkas lamaran kerja, dan mengerjakan tes tertulis secara online[3]. Serta pihak perusahaan akan mendapatkan karyawan melalui cara yang efektif dengan waktu yang efisien, dimulai dari penyampaian informasi, penyeleksian berkas, tes tertulis dan hasil kelulusan dari tes tertulis yang bisa langsung di proses melalui sistem informasi ini.

\section{METODE PENELITIAN}

\subsection{Tahapan Penelitian}

Metode penelitian pada penelitian ini dilakukan beberapa tahap seperti penjelasan di bawah ini :

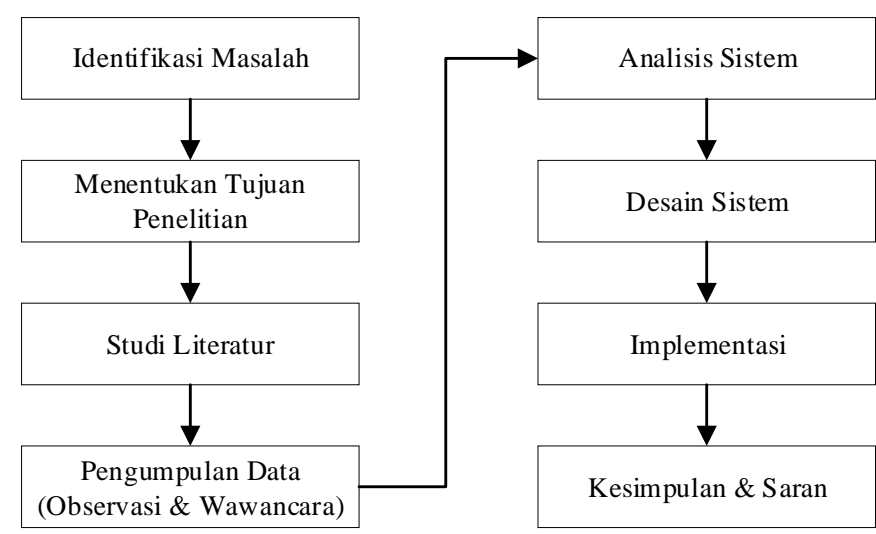

Gambar 1. Tahap-Tahap Penelitian

Langkah-langkah dalam penelitian ini meliputi tahapan-tahapan sebagai berikut :

1. Tahap Awal

Adapun kegiatan yang dilakukan pada tahap awal adalah :

a. Identifikasi masalah

b. Menentukan tujuan penelitian

c. Studi literatur

d. Pengumpulan data (observasi dan wawancara)

2. Tahap pengembangan

Adapun tahap pengembangan sebagai berikut :

a. Analisis sistem

b. Desain sistem

3. Tahap Akhir

a. Implementasi

b. Kesimpulan dan saran

\subsection{Lowongan}

Lowongan berasal dari kata dasar lowong. Menurut Kamus Bahasa Indonesia, lowong adalah kosong, terluangnya suatu jabatannya sehingga dapat ditempatkan oleh seseorang. Dapat disimpulkan untuk pengertian lowongan adalah tersedianya posisi jabatan yang kosong sehingga dapat ditempati oleh seseorang untuk bekerja [4].

\subsection{Rekrutmen}

Pengertian rekrutmen adalah putusan sumber daya manusia (SDM) berupa banyak dibutuhkan, kapan dibutuhkan, serta pengetahuan, keterampilan, kemampuan khusus yang dimiliki. Perekrutan karyawan merupakan suatu proses atau tindakan yang dilakukan oleh organisasi untuk mendapatkan tambahan karyawan melalui beberapa tahapan mencakup identifikasi dan evaluasi sumber-sumber perekrutan tenaga kerja, menentukan kebutuhan tenaga kerja, proses seleksi, penempatan, dan orientasi tenaga kerja. Perekrutan karyawan bertujuan menyediakan karyawan yang cukup agar manajemen dapat memilih karyawan yang memenuhi kualifikasi yang mereka perlukan. Rekrutmen merupakan proses komunikasi dua arah. Para pelamar menghendaki informasi yang akurat mengenai seperti apakah rasanya bekerja di dalam organisasi bersangkutan. Organisasi-organisasi sangat menginginkan informasi yang akurat tentang seperti apakah pelamar-pelamar tersebut jika kelak mereka diangkat sebagai karyawan [5]-[7]. 


\section{ANALISIS DAN PEMBAHASAN}

Analisis sistem adalah teknik menguraikan sebuah sistem yang utuh dan bagian-bagiannya dengan tujuan mengidentifikasi masalah untuk mencari kelemahan sistem.

\section{a. Deskripsi Sistem}

Berdasarkan hasil pengamatan yang dilakukan terdahap sistem pengolahan data yang sedang berjalan pada lowongan pekerjaan ini, dapat dideskripsikan sebagai berikut :

1. Perusahaan membuka lowongan pekerjaan.

2. Pelamar melengkapi persyaratan apa saja yang diperlukan pada lamaran pekerjaan tersebut.

3. Pelamar mengirim berkas ke perusahaan.

4. HRD menyeleksi berkas dengan cara menyesuaikan persyaratan yang diperlukan perusahaan.

5. Jika lulus, pelamar melanjutkan tes tertulis yang dipersiapkan oleh perusahaan.

6. Jika lulus, pelamar melanjutkan tes wawancara dengan HRD.

7. Jika lulus, pelamar dibuatkan perjanjian kontrak kerja dan telah menjadi karyawan perusahaan.

8. Karyawan mulai bekerja.

\section{b. Kelemahan Sistem}

Berdasarkan deskripsi sistem di atas, dapat diketahui kekurangan-kekurangan yang menjadi kelemahan dalam sistem tersebut. Beberapa kelemahan tersebut adalah sebagai berikut :

1. Permasalahan yang ada pada perusahaan

a. Dengan sistem manual yang ada, maka akan memperlambat kerja perusahaan dalam tahapan-tahapan penerimaan karyawan.

b. Dengan melakukan tes tertulis secara manual, maka perusahaan harus mencetak lembar soal dan jawaban, serta harus menambah SDM untuk melakukan pemeriksaan hasil tes. Hal ini akan banyak memakan biaya.

c. Informasi penerimaan karyawan belum terdokumentasi dan tersimpan di dalam database sehingga mudah hilang.

2. Permasalahan yang ada pada pelamar

a. Waktu yang digunakan untuk mencari informasi lowongan pekerjaan terbatas hanya pada jam kerja.

b. Belum mempunyai media yang bersifat luas untuk melakukan komunikasi di luar jam kerja dalam hal penerimaan karyawan.

c. Jika pelamar datang dari luar kota merasa berat jika harus datang berkali-kali untuk mengikuti tahapantahapan dalam penerimaan karyawan.

\subsection{Rancangan Sistem Baru}

Berdasarkan hasil analisis dan deskripsi sistem di atas telah diketahui beberapa kelemahan dan kekurangan pada sistem yang sedang berjalan. Untuk mengatasi kelemahan dan kekurangan sistem tersebut, maka harus dilakukan perbaikan sistem, yaitu dengan menambahkan alat bantu berupa sistem komputerisasi yang dirancang untuk menangani data-data serta proses-proses dengan cepat, tepat, akurat dan dapat dipertanggungjawabkan. Tujuan utama dari sebuah sistem adalah untuk memberikan gambaran tentang model sistem baru yang akan diterapkan baik dari sisi input, proses maupun output sistem tersebut.

\section{a. Deskripsi Sistem yang Diusulkan}

Sistem baru yang diusulkan bertujuan untuk membantu dan mempermudah dalam melaksanakan publikasi lowongan pekerjaan dan pencarian lowongan pekerjaan dengan mengautomatisasi yang bersifat secara mudah, praktis dan menghemat waktu. Berikut beberapa spesifikasi kebutuhan dari sistem ini :

1. Untuk Pelamar:

a. Pelamar bisa melihat home.

b. Pelamar bisa melihat profil perusahaan.

c. Pelamar bisa melihat lowongan kerja.

d. Pelamar bisa mendaftarkan diri sebagai data pendaftar.

e. Pendaftar bisa login sebagai pelamar.

f. Pelamar bisa melihat kontak perusahaan.

g. Pelamar dapat mengisi data pelamar.

h. Pelamar dapat mengerjakan tes.

i. Pelamar dapat melihat hasil tes.

2. Untuk Admin / HRD :

a. Admin dapat mengelola data pelamar

b. Admin dapat mengelola soal dan jawaban.

c. Admin dapat mengelola data berkas pelamar.

d. Admin dapat mengelola data hasil tes.

e. Admin dapat mengelola info. 
Building of Informatics, Technology and Science (BITS)

Volume 2, No 2, December 2020 Page 84-90

ISSN 2684-8910 (media cetak)

ISSN 2685-3310 (media online)

\section{b. Desain Model Sistem}

Model dari sistem informasi yang dirancang dalam bentuk logika. Pemodelan tersebut digambarkan dalam beberapa bagan, diantaranya :

1. Context Diagram

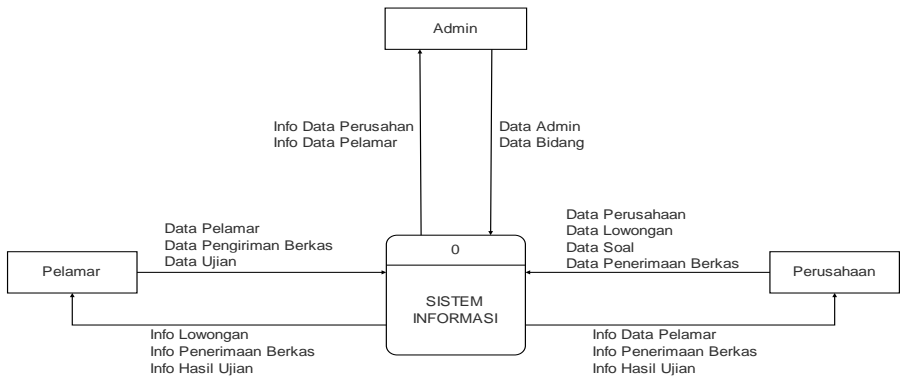

Gambar 2. Context Diagram

2. Data Flow Diagram

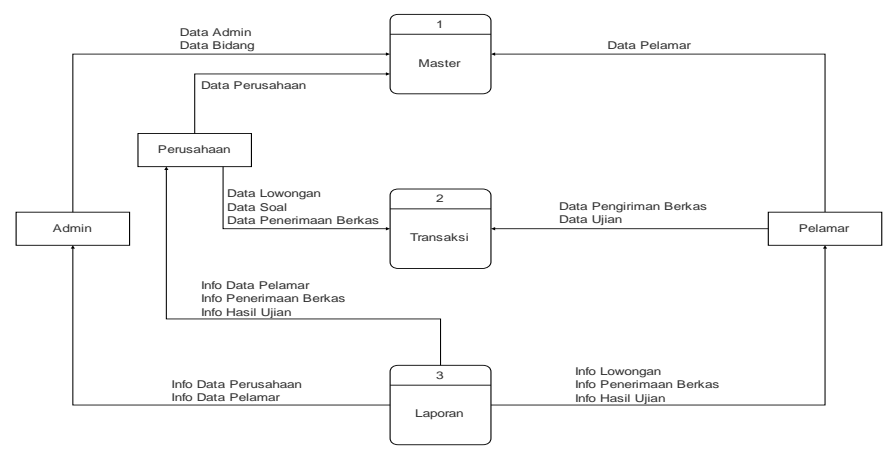

Gambar 3. Data Flow Diagram

3. Entity Relationship Diagram (ERD)

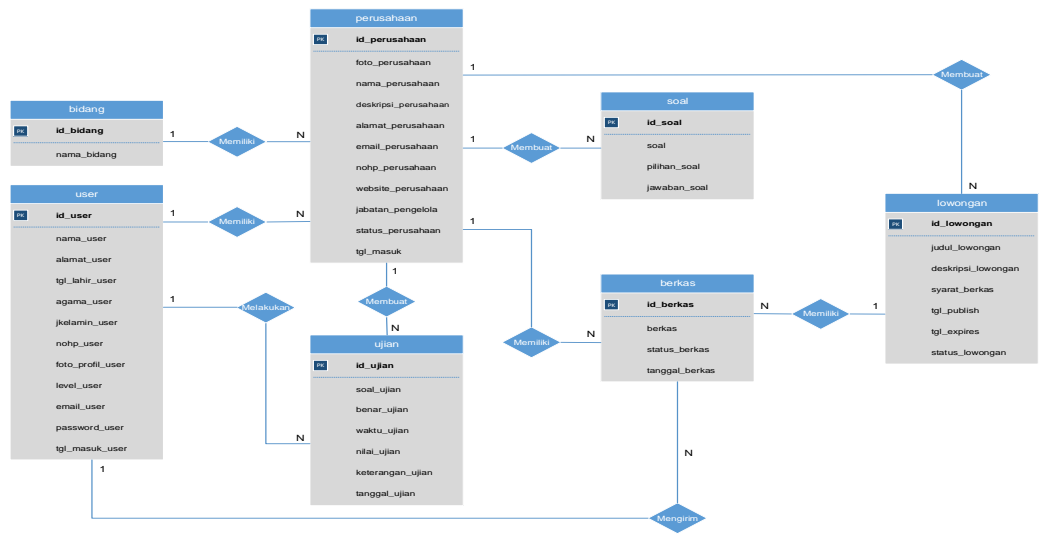

Gambar 4. Entity Relationship Diagram (ERD)

4. Relational Data Model (RDM)

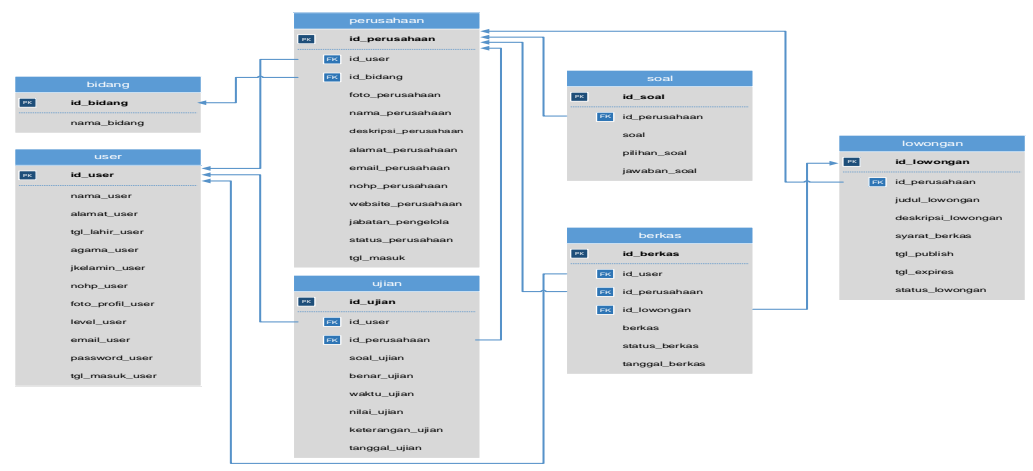

Gambar 5. Relational Data Model (RDM)

Puput Nada Musfika, Copyright (C) 2020, BITS | Page 87 Submitted: 24/10/2020; Accepted: 13/11/2020; Published: 10/12/2020 
Building of Informatics, Technology and Science (BITS)

Volume 2, No 2, December 2020 Page 84-90

ISSN 2684-8910 (media cetak)

ISSN 2685-3310 (media online)

\subsection{Implementasi Sistem Informasi Lowongan Kerja Di Kota Sampit Berbasis Web}

Implementasi sistem informasi lowongan kerja di kota Sampit berbasis web merupakan cara penerapan suatu sistem dan cara menjalankan program aplikasi sistem informasi lowongan kerja di kota Sampit berbasis web.

a. Halaman Utama

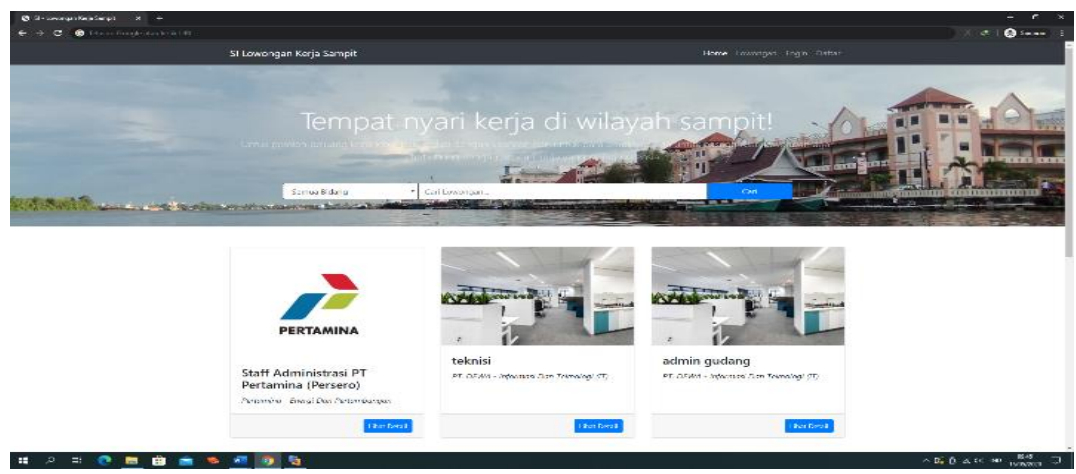

Gambar 6. Halaman Utama

b. Halaman Daftar

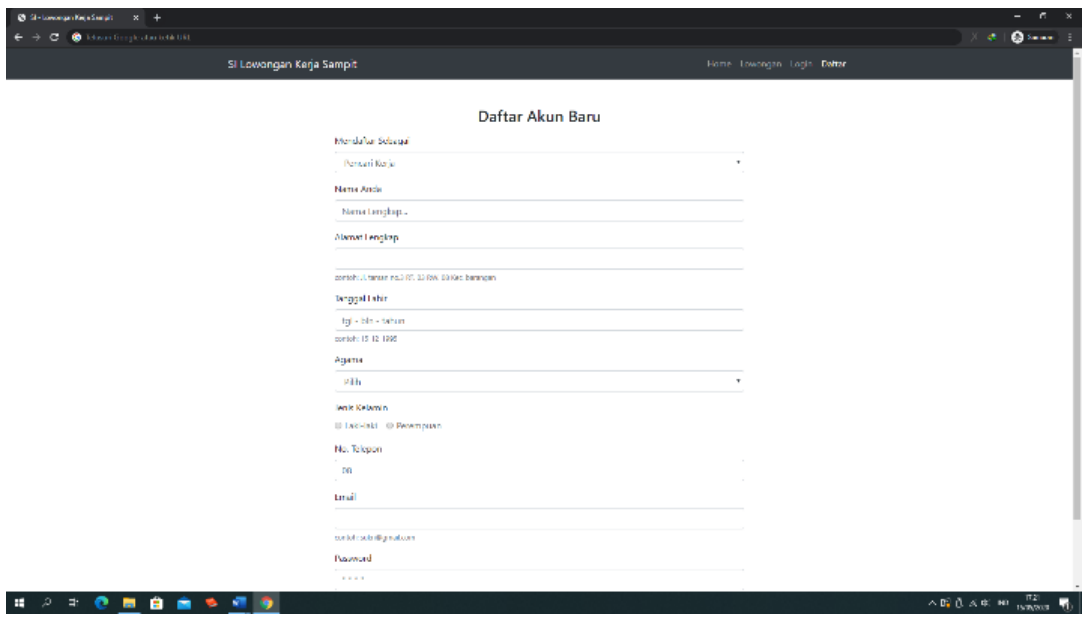

Gambar 7. Halaman Daftar

c. Halaman Login
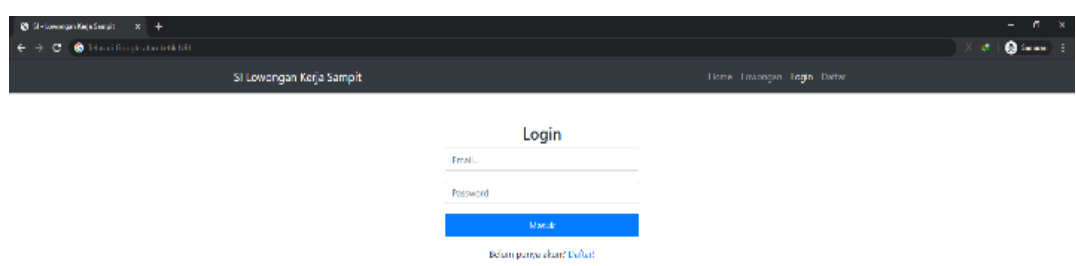

d. Halaman Data User

Gambar 8. Halaman Login

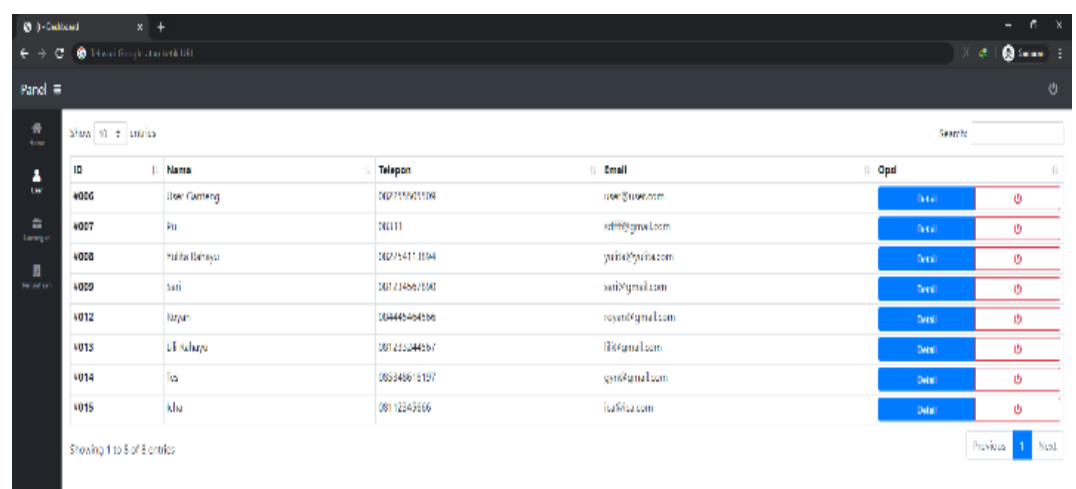

Gambar 9. Halaman Data User

Puput Nada Musfika, Copyright (C) 2020, BITS | Page 88 Submitted: 24/10/2020; Accepted: 13/11/2020; Published: 10/12/2020 
Building of Informatics, Technology and Science (BITS)

Volume 2, No 2, December 2020 Page 84-90

ISSN 2684-8910 (media cetak)

ISSN 2685-3310 (media online)

e. Halaman Data Perusahaan

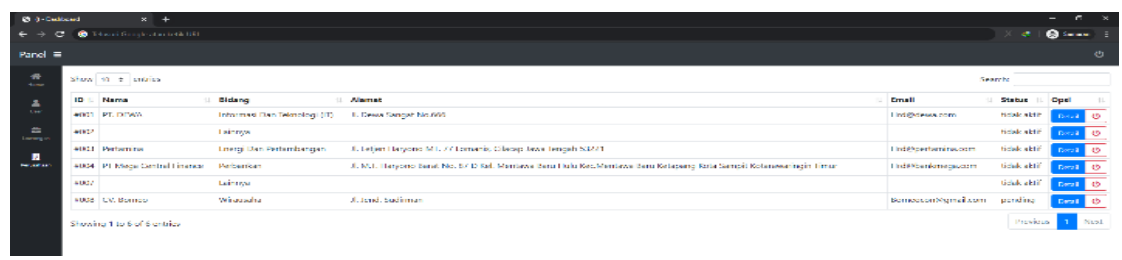

Gambar 10. Halaman Data Perusahaan

f. Halaman Data Lowongan

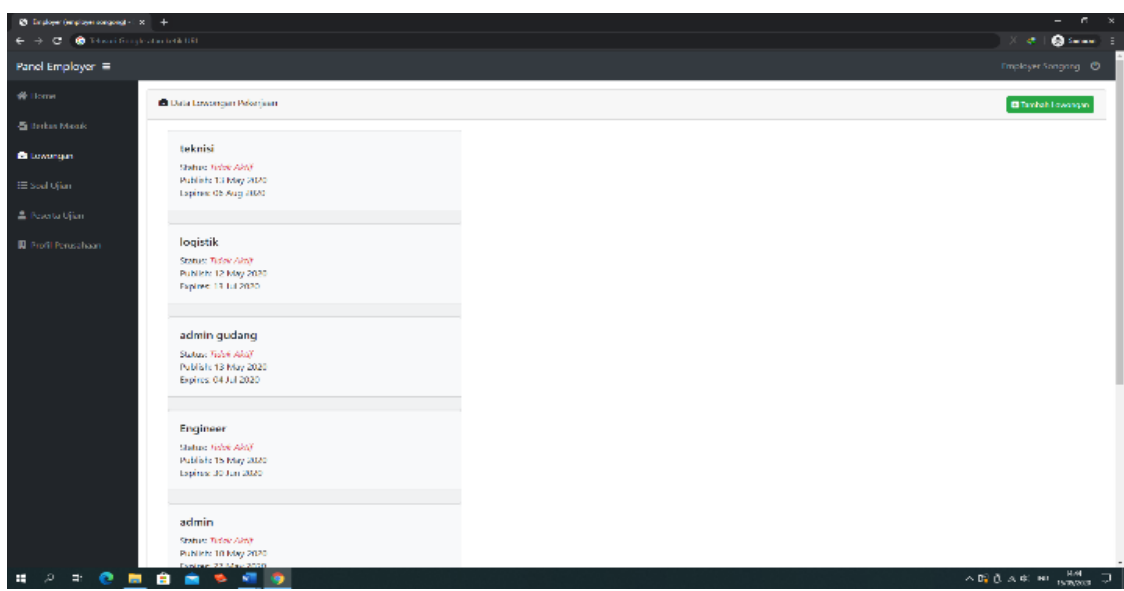

Gambar 11. Halaman Data Lowongan

g. Halaman Data Soal Ujian

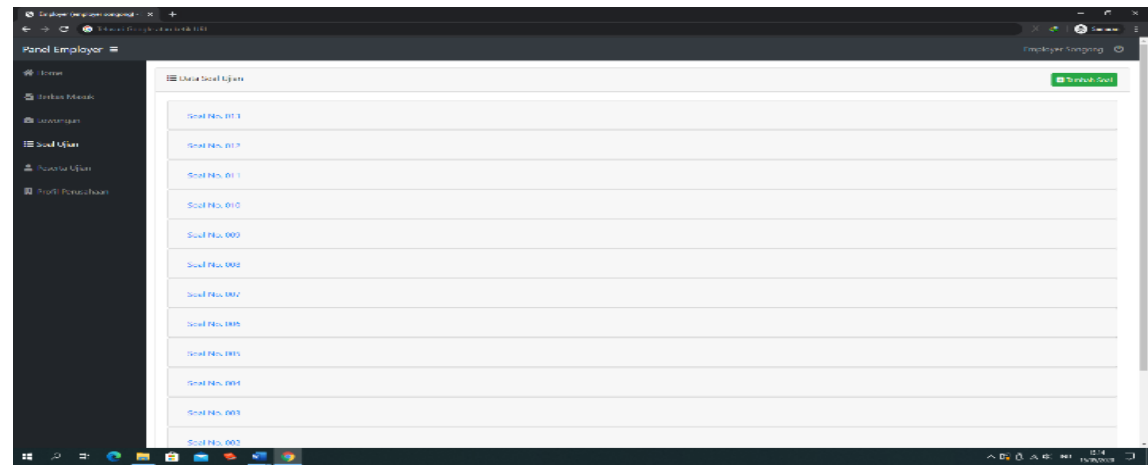

Gambar 12. Halaman Data Soal Ujian

h. Halaman Detail Lowongan Pekerjaan

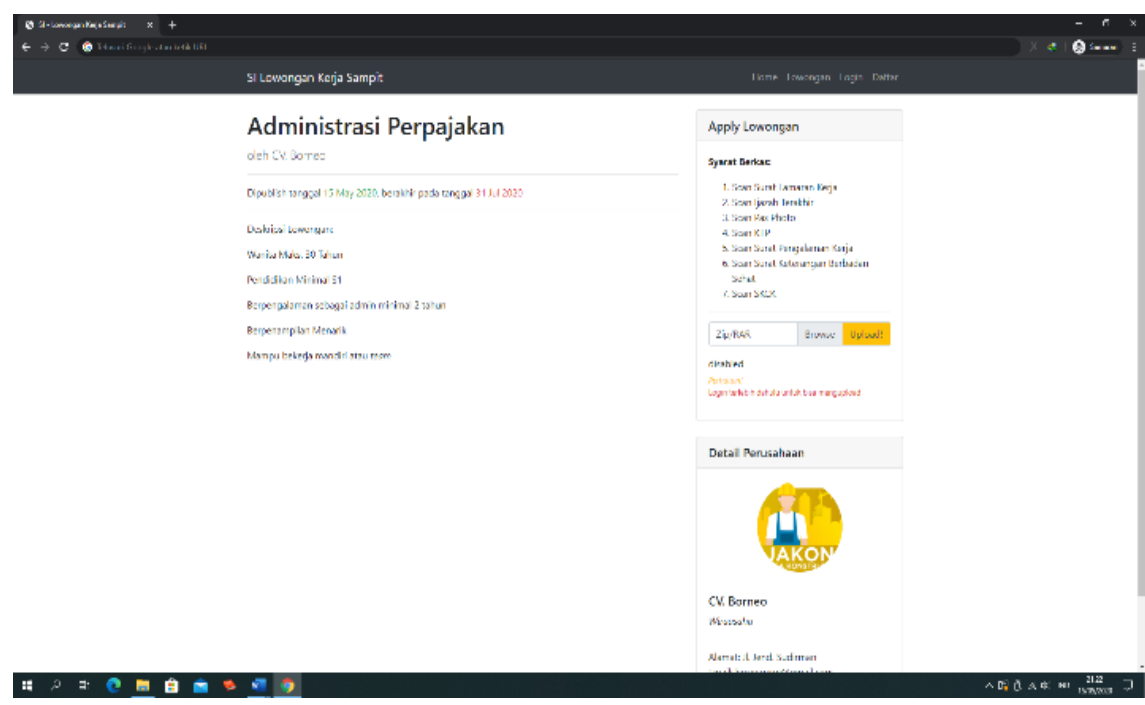

Gambar 13. Halaman Detail Lowongan Pekerjaan

Puput Nada Musfika, Copyright $@$ 2020, BITS | Page 89 Submitted: 24/10/2020; Accepted: 13/11/2020; Published: 10/12/2020 
Building of Informatics, Technology and Science (BITS)

Volume 2, No 2, December 2020 Page 84-90

ISSN 2684-8910 (media cetak)

ISSN 2685-3310 (media online)

i. Halaman Data Berkas Masuk

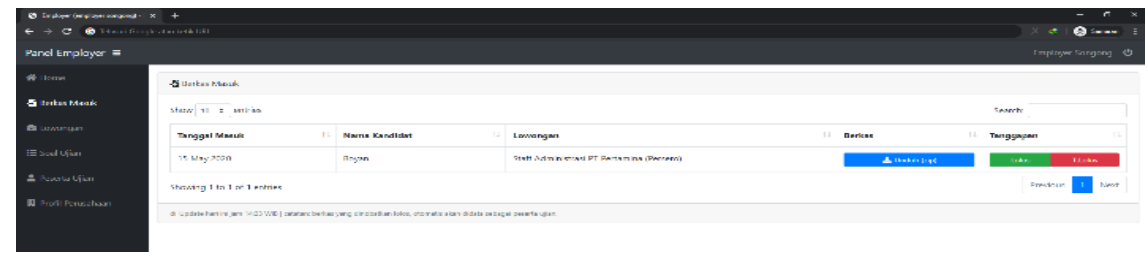

Gambar 14. Halaman Data Lamaran Pekerjaan

j. Halaman Data Peserta Ujian

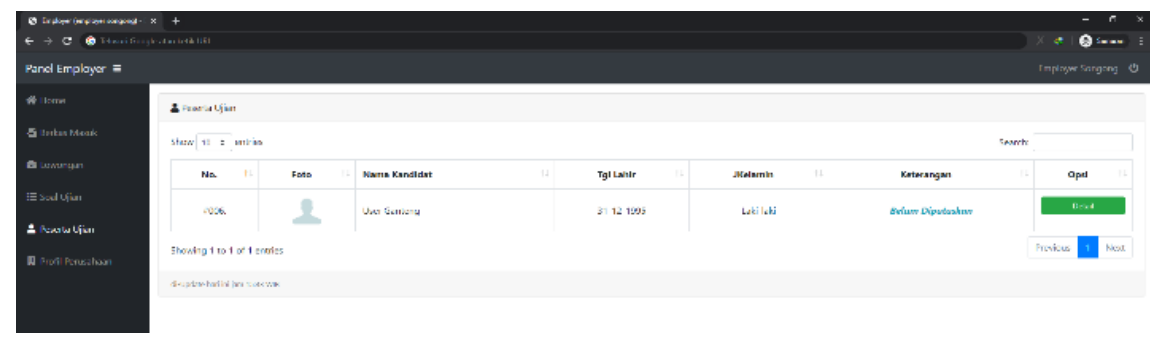

Gambar 15. Halaman Data Peserta Ujian

\section{KESIMPULAN}

Dari keseluruhan pembahasan di atas dapat disimpulkan dengan sistem informasi ini sudah dapat memberikan informasi lowongan kerja kepada pelamar pekerjaan di kota Sampit. Sistem informasi ini sudah dapat mempermudah pelamar kerja untuk penyerahan berkas lamaran dan melakukan tes tertulis secara online. Sistem informasi ini sudah dapat mempermudah pihak perusahaan untuk mendapatkan calon karyawan. Berdasarkan pada kesimpulan yang ada, maka disarankan menyarankan beberapa hal yang perlu diperhatikan pada program aplikasi yang telah dibuat, yakti melakukan pengembangan sistem, agar jaringan penyedia dan pencari kerja lebih luas lagi tidak hanya di kota Sampit saja. Menambahkan fitur upload berkas secara satu persatu, agar meminimalisir kekurangan persyaratan upload berkas.

\section{REFERENCES}

[1] J. Simarmata, Pengenalan Teknologi Komputer dan Informasi. Yogyakarta: Andi, 2006.

[2] J. Simarmata, Rekayasa Web. Andi, 2010.

[3] J. Hutahaean, Konsep Sistem Informasi. Deepublish, 2018.

[4] B. Susilawati, "Rancang Bangun Sistem Informasi Lowongan Pekerjaan Berbasis Web," vol. 16, 2018.

[5] A. Astriany Rizky and I. Ramdhani, "PERANCANGAN SISTEM INFORMASI PEREKRUTAN KARYAWAN BERBASIS WEB MENGGUNAKAN PHP DAN MYSQL DI PT. RIA INDAH MANDIRI,” vol. 9, 2019.

[6] N. I. Sarumaha, M. Simanungkalit, and M. Damanik, "Sistem Pendukung Keputusan Penerimaan Pegawai Baru Menerapkan Metode VIKOR dan MOORA," Semin. Nas. Sains Teknol. dan Informasi(SENSASI), no. ISBN: 978-602-52720-0-4, pp. 193-214, 2018.

[7] D. M. Ariyanti, F. Agus, and D. M. Khairina, "Sistem Pendukung Keputusan Untuk Seleksi Penerimaan Dan Penentuan Posisi Karyawan," J. Inform. Mulawarman, vol. 10, no. 1, 2015 